\title{
Minimally invasive glaucoma surgery - current and emerging techniques to reduce intraocular pressure and medications
}

\author{
Krishna Komzak ${ }^{1}$, Philip Rothschild ${ }^{1,2,3}$, Joobin Hooshmand ${ }^{4}$, Penny Allen ${ }^{2,5}$, Tze'Yo Toh ${ }^{6}$ \\ 'Launceston Clinical School, College of Health and Medicine, University of Tasmania, Tasmania, Launceston 7250, Australia. \\ ${ }^{2}$ Tasmanian Eye Institute, Tasmania, Launceston 7250, Australia. \\ ${ }^{3}$ Alfred Health, Victoria, Melbourne 3000, Australia. \\ ${ }^{4}$ Sydney Eye Hospital, New South Wales, Sydney 2000, Australia. \\ ${ }^{5}$ Rural Clinical School, College of Health and Medicine, University of Tasmania, Tasmania, Burnie 7320, Australia. \\ ${ }^{6}$ Launceston Eye Doctors, Tasmania, Launceston 7250, Australia.
}

Correspondence to: Mr. Krishna Komzak, Launceston Clinical School, College of Health and Medicine, University of Tasmania, 41 Charles Street, Tasmania, Launceston 7250, Australia.Email: komzakk@utas.edu.au

\begin{abstract}
How to cite this article: Komzak K, Rothschild P, Hooshmand J, Allen P, Toh T. Minimally invasive glaucoma surgery - current and emerging techniques to reduce intraocular pressure and medications. Mini-invasive Surg 2021;5:13.
\end{abstract}

http://dx.doi.org/10.20517/2574-1225.2020.103

Received: 10 Nov 2020 First Decision: 5 Jan 2021 Revised: 24 Jan 2021 Accepted: 22 Feb 2021 Published: 12 Mar 2021

Academic Editors: Kazuyuki Hirooka, Giulio Belli Copy Editor: Xi-Jun Chen Production Editor: Xi-Jun Chen

\begin{abstract}
Minimally invasive glaucoma surgery (MIGS) has become increasingly popular as a step in the management pathway of open angle glaucoma. Due to the relative novelty of these devices, there remains some paucity of evidence relating to their long-term efficacy and safety, and this can make comparison between these techniques somewhat complex. This review article aims to guide clinical decision making by providing the latest evidence on the comparative efficacy of current iterations of minimally invasive glaucoma surgery. A literature review was conducted to identify the most significant recent evidence to support the safety and efficacy of the various forms of minimally invasive glaucoma surgery. Included studies provided efficacy and safety data on a variety of minimally invasive glaucoma surgery methods. The PubMed database was searched and a total of 484 studies, published between 2015 and 2020 were identified, of which 27 were included. The studies indicate that most available forms of minimally invasive glaucoma surgery show statistically significant efficacy in terms of intraocular pressure reduction and improvement in medication burden, while maintaining an acceptable safety profile.
\end{abstract}

Keywords: Minimally invasive glaucoma surgery, open angle glaucoma, trabecular microbypass, ab-interno canaloplasty, trabeculectomy, suprachoroidal, subconjunctival

\footnotetext{
(@) ( $)$

(C) The Author(s) 2021. Open Access This article is licensed under a Creative Commons Attribution 4.0 International License (https://creativecommons.org/licenses/by/4.0/), which permits unrestricted use, sharing, adaptation, distribution and reproduction in any medium or format, for any purpose, even commercially, as long as you give appropriate credit to the original author(s) and the source, provide a link to the Creative Commons license, and indicate if changes were made.
}

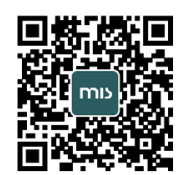




\section{INTRODUCTION}

Minimally invasive glaucoma surgery (MIGS) is an emerging field in open angle glaucoma (OAG) management with a promise to offer a reduction in intra-ocular pressure (IOP) and medication burden without the comparatively high risk of complications associated with more invasive incisional procedures. Glaucoma is characterized by progressive optic neuropathy that is associated with progressive field loss in which IOP is a key modifiable factor. Current established management options to reduce IOP primarily revolve around topical medications or application of selective laser trabeculoplasty (SLT) or a combination of both. Failing these, patients will often require invasive and complicated surgery to avoid blindness. In recent years, however, MIGS has heralded a new dawn in reducing IOP for glaucoma patients.

\section{Topical medications for glaucoma}

The main aim of topical therapy is to reduce IOP and to do so with fewer medications and side effects as possible (summarised below in Table 1 in order of treatment preference) ${ }^{[1]}$. The first-line topical agents in OAG are the prostaglandin analogues, which utilise the uveoscleral pathway to increase outflow of aqueous humor and are usually taken as a single dose at night. These medications cause minimal systemic adverse events, but local adverse events including conjunctival hyperaemia, periocular darkening, iris darkening, eyelash darkening and lengthening, macular oedema, and uveitis are known to occur. Secondline agents include $\beta$-adrenergic blockers, $\alpha$-agonists, carbonic anhydrase inhibitors, and cholinergic agonists, and are used when prostaglandin analogues are insufficient to control IOP or are contraindicated. Many of these medications cause local and systemic side effects including ocular irritation and dry eye. b-adrenergic blockers in particular are contraindicated in chronic obstructive pulmonary disease, asthma and bradycardia due to their systemic effects ${ }^{[1]}$.

\section{Alternatives to topical medications}

While medications can significantly reduce the disease progression of OAG with ideal use, they are limited by inconsistent compliance and their associated side effect profile. Compliance can be affected by a multiplicity of medications and long duration of treatment. A recent study of 128 South Australian patients found that for patients on long-term topical glaucoma therapy, the maximal adherence level was as low as $41.4 \%$. The primary reason for poor compliance was reported as poor memory or forgetfulness ${ }^{[2]}$. For this reason, medications are often inferior to surgical intervention as they require long-term compliance, and in this case only an estimated $41.4 \%$ of patients are truly seeing the full effect of treatment, in comparison with surgery where ongoing effect is not reliant on the patient's ability to comply with the treatment regimen.

For severe OAG that is uncontrolled with medications, trabeculectomy is the most common IOP-lowering surgery performed; however, it is an invasive procedure and carries a significant risk of complications. A recent Cochrane review of five studies showed that complications are comparatively likely with trabeculectomy. These include hyphaema (seen in $13.1 \%$ of eyes), shallow anterior chamber (14.1\%), choroidal detachment $(14.1 \%)$, postoperative IOP spike (2.1\%), anterior chamber inflammation (7.3\%), hypotony $(15.6 \%)$ and accelerated cataract progression $(13.7 \%)^{[3]}$. An alternative to trabeculotomy is laser trabeculoplasty, which is a less invasive in-office procedure that can lead to significant IOP reductions; however, it is less effective than undergoing a trabeculectomy, with a $10 \%$ failure rate per year ${ }^{[1]}$. In addition to these methods, whilst cataract surgery is traditionally performed to treat vision distortion, it is also a proven effective adjunct in the management of glaucoma. Phacoemulsification alone has been shown to cause a mean reduction in IOP of $5.3 \pm 3.9 \mathrm{mmHg}$ and reduce mean medication burden from $1.7 \pm 0.9$ to $0.7 \pm 0.9$ at 24 months as a standalone procedure ${ }^{[4]}$.

\section{What is minimally invasive glaucoma surgery?}

Given the limited success profile of current treatments, MIGS has become increasingly popular as a form of treatment for glaucoma. There are numerous MIGS approaches, including: (1) increasing flow through the 
Table 1. Summary of current medical glaucoma treatment

\begin{tabular}{|c|c|c|c|c|}
\hline Medication class & Examples & Mode of action & Adverse effects & Precautions \\
\hline $\begin{array}{l}\text { Prostaglandin } \\
\text { analogues }\end{array}$ & $\begin{array}{l}\text { Travoprost } \\
\text { Bimatoprost } \\
\text { Latanoprost } \\
\text { Tafluprost } \\
\text { Unoprostone }\end{array}$ & $\begin{array}{l}\text { Increasing uveoscleral outflow of } \\
\text { aqueous humour }\end{array}$ & $\begin{array}{l}\text { Iris hyperpigmentation } \\
\text { Darkening/discolouration lid/ } \\
\text { conjunctival oedema } \\
\text { Uveitis or iritis } \\
\text { Macular oedema }\end{array}$ & $\begin{array}{l}\text { Iritis/uveitis } \\
\text { Herpetic keratitis } \\
\text { Aphakia } \\
\text { Pregnancy }\end{array}$ \\
\hline $\begin{array}{l}\beta \text {-adrenergic } \\
\text { blockers }\end{array}$ & $\begin{array}{l}\text { Timolol } \\
\text { Betaxolol } \\
\text { Carteolol } \\
\text { Metipranolol } \\
\text { Levubunolol }\end{array}$ & $\begin{array}{l}\text { Suppress aqueous humour } \\
\text { production }\end{array}$ & $\begin{array}{l}\text { Blurred vision } \\
\text { Stinging } \\
\text { Bradycardia }\end{array}$ & $\begin{array}{l}\text { Systemic beta blockade } \\
\text { Asthma } \\
\text { COPD } \\
\text { Bradyarrhythmia }\end{array}$ \\
\hline $\begin{array}{l}\alpha \text {-adrenergic } \\
\text { agonists }\end{array}$ & $\begin{array}{l}\text { Apraclonidine } \\
\text { Brominidine }\end{array}$ & $\begin{array}{l}\text { Suppress aqueous humour } \\
\text { production and increased } \\
\text { uveoscleral outflow }\end{array}$ & $\begin{array}{l}\text { Ocular allergy } \\
\text { Hyperaemia } \\
\text { Ocular irritation } \\
\text { Dry mouth and nose } \\
\text { Taste disturbance } \\
\text { Headache }\end{array}$ & $\begin{array}{l}\text { Severe cardiovascular } \\
\text { disease }\end{array}$ \\
\hline $\begin{array}{l}\text { Carbonic anhydrase } \\
\text { inhibitors }\end{array}$ & $\begin{array}{l}\text { Brinzolamide } \\
\text { Dorzolamide } \\
\text { Acetazolamide }\end{array}$ & $\begin{array}{l}\text { Suppress aqueous humor } \\
\text { production }\end{array}$ & $\begin{array}{l}\text { Ocular irritation } \\
\text { Transient blurred vision } \\
\text { Foreign body sensation } \\
\text { Bitter taste }\end{array}$ & $\begin{array}{l}\text { Compromised corneal } \\
\text { endothelium } \\
\text { Pregnancy }\end{array}$ \\
\hline Cholinergic agonists & $\begin{array}{l}\text { Pilocarpine } \\
\text { Carbachol }\end{array}$ & $\begin{array}{l}\text { Increased trabecular aqueous } \\
\text { humour outflow }\end{array}$ & $\begin{array}{l}\text { Blurred vision } \\
\text { Myopia } \\
\text { Ocular irritation } \\
\text { Headache }\end{array}$ & $\begin{array}{l}\text { Uveitis } \\
\text { Iritis } \\
\text { Risk of retinal detachment } \\
\text { Heavily pigmented eyes }\end{array}$ \\
\hline
\end{tabular}

Summary of current glaucoma medications in descending order of treatment preference. COPD: Chronic obstructive pulmonary disease ${ }^{[1]}$.

trabecular meshwork and Schlemm's canal; (2) directing flow through the supraciliary space; (3) directing aqueous outflow to the subconjunctival space; and (4) reducing the production of aqueous fluid at the ciliary processes.

All of these methods share some common features including an ab-interno approach which spares incision of the sclera, leading to a more favourable side effect profile compared with some other traditional pressure lowering procedures such as trabeculectomy or ab-externo drainage devices. However, one important distinction is that MIGS generally leads to a smaller reduction in intra-ocular pressure than more invasive approaches, and for this reason it is important to consider the individual patient needs prior to deciding upon the glaucoma management.

In this study a literature review was performed, assessing the different types of MIGS procedures and providing an overview of their comparable efficacy in an effort to inform clinical decision making and bring attention to the variety of MIGS available.

\section{METHODS}

A literature review was performed to identify studies that evaluated the efficacy and safety of various MIGS procedures. For the purposes of this review, included studies had to provide data on currently available forms of MIGS in terms of IOP and medication reductions, and also comment on the safety profile of these devices. In the case of emerging MIGS, studies were included if they gave a description of these devices or included a description of upcoming trials. Exclusion criteria included non-English language papers, nonhuman research, case studies and articles written before the 1st of January 2015.

The electronic database used for this literature review was PubMed. The database was searched in October 2020. The search was limited to articles published from January 1, 2015 to October 9, 2020 in the English language. The search terms were: [(MIGS OR micro invasive OR micro bypass OR stent) AND (glaucoma 
Table 2. Summary of efficacy results from studies included in the review

\begin{tabular}{|c|c|c|c|c|c|c|}
\hline Technique & Study & $\begin{array}{c}\text { Combination/ } \\
\text { standalone }\end{array}$ & $\begin{array}{l}\text { Study } \\
\text { design }\end{array}$ & Population & IOP change (\%) & $\begin{array}{c}\text { Medication } \\
\text { reduction }\end{array}$ \\
\hline \multicolumn{7}{|l|}{ Schlemm's canal } \\
\hline iStent & $\begin{array}{l}\text { Hooshmand et al. }{ }^{[5]} \\
\text { Ferguson et al. } .^{[6]} \\
\text { Ferguson et al. }{ }^{[7]} \\
\text { Ahmed et al. }{ }^{[8]} \\
\text { Katz et al. }{ }^{[9]}\end{array}$ & $\begin{array}{l}+\mathrm{CE} \\
+\mathrm{CE} \\
+\mathrm{CE} \\
+\mathrm{CE} \\
\text { Standalone }\end{array}$ & $\begin{array}{l}\text { PCS } \\
\text { RCS } \\
\text { RCS } \\
\text { RCT } \\
\text { RCT }\end{array}$ & $\begin{array}{l}245 \text { eyes } \\
24 \text { eyes } \\
115 \text { eyes } \\
75 \text { eyes } \\
119 \text { subjects }\end{array}$ & $\begin{array}{l}18 \text { mo: }-13.23 \\
36 \text { mo: }-24.72 \\
24 \text { mo: }-27.45 \\
12 \text { mo: }-5.24 \\
42 \text { mo: }-21.89\end{array}$ & $\begin{array}{l}18 \text { mo: }-0.8 \\
36 \text { mo: }-0.16 \\
24 \text { mo: }-0.7 \\
12 \text { mo: }-1.0 \\
42 \text { mo: }-1.65\end{array}$ \\
\hline iStent inject & $\begin{array}{l}\text { Hooshmand et al.. } \\
\text { Samuelson et al. }\end{array}$ & $\begin{array}{l}+C E \\
+C E\end{array}$ & $\begin{array}{l}\text { PCS } \\
\text { RCT }\end{array}$ & $\begin{array}{l}245 \text { eyes } \\
505 \text { eyes }\end{array}$ & $\begin{array}{l}18 \mathrm{mo}:-11.64 \\
24 \mathrm{mo}:-40\end{array}$ & $\begin{array}{l}18 \text { mo: }-0.8 \\
24 \text { mo: }-1.2\end{array}$ \\
\hline Hydrus & $\begin{array}{l}\text { Samuelson et al. } \\
\text { Ahmed et al. }\end{array}$ & $\begin{array}{l}+C E \\
+C E\end{array}$ & $\begin{array}{l}\text { RCT } \\
\text { RCT }\end{array}$ & $\begin{array}{l}556 \text { eyes } \\
73 \text { eyes }\end{array}$ & $\begin{array}{l}24 \text { mo: }-43.68 \\
12 \text { mo: }-8.95\end{array}$ & $\begin{array}{l}24 \text { mo: }-1.4 \\
12 \text { mo: }-1.6\end{array}$ \\
\hline $\mathrm{ABiC}$ & $\begin{array}{l}\text { Davids et al. }{ }^{[11]} \\
\text { Heersink et }^{\left[1 .^{[12]}\right.}\end{array}$ & $\begin{array}{l}+/-C E \\
+C E+i S t e n t\end{array}$ & $\begin{array}{l}\text { RCS } \\
\text { RCS }\end{array}$ & $\begin{array}{l}36 \text { eyes } \\
86 \text { eyes }\end{array}$ & $\begin{array}{l}12 \text { mo: }-30.3 \\
6 \text { mo: }-17.47\end{array}$ & $\begin{array}{l}12 \text { mo: }-0.37 \\
6 \text { mo: }-0.9\end{array}$ \\
\hline Trabectome & $\begin{array}{l}\text { Esfandiari et al. }{ }^{[13]} \\
\text { Avar et al. }{ }^{[14]}\end{array}$ & $\begin{array}{l}+\mathrm{CE} \\
+/-\mathrm{CE}\end{array}$ & $\begin{array}{l}\text { RCS } \\
\text { RCS }\end{array}$ & $\begin{array}{l}154 \text { eyes } \\
154 \text { eyes }\end{array}$ & $\begin{array}{l}24 \text { mo: }-9.15 \\
60 \text { mo: }-25.22\end{array}$ & $\begin{array}{l}24 \text { mo: }-0.6 \\
60 \text { mo: }-1.3\end{array}$ \\
\hline GATT & Olgun et al. ${ }^{[15]}$ & $+/-C E$ & RCS & 107 eyes & 24 mo: -38.55 & 24 mo: -2.1 \\
\hline Goniotomy & Elmallah et al. ${ }^{[16]}$ & $+C E$ & RCS & 315 eyes & 12 mo: -27.47 & 12 mo: -1.03 \\
\hline \multicolumn{7}{|c|}{ Supraciliary space/ciliary process } \\
\hline CyPass & $\begin{array}{l}\text { Vold et al. }{ }^{[17]} \\
\text { Reiss et al. } \\
\text { Fard et al. }{ }^{[19]} \\
\text { Fard et al. }{ }^{[19]}\end{array}$ & $\begin{array}{l}+\mathrm{CE} \\
+\mathrm{CE} \\
+\mathrm{CE} \\
\text { Standalone }\end{array}$ & $\begin{array}{l}\text { RCT } \\
\text { RCT } \\
\text { SR/MA } \\
\text { SR/MA }\end{array}$ & $\begin{array}{l}374 \text { subjects } \\
215 \text { subjects } \\
274 \text { subjects } \\
182 \text { subjects }\end{array}$ & $\begin{array}{l}24 \text { mo: }-30.33 \\
60 \text { mo: }-34.29 \\
24 \text { mo: }-35.7 \\
24 \text { mo: }-16.1\end{array}$ & $\begin{array}{l}24 \text { mo: }-1.2 \\
\text { n/a } \\
24 \text { mo: }-0.66 \\
24 \text { mo: }-1.24\end{array}$ \\
\hline iStent Supra & Myers et al. ${ }^{[20]}$ & +2 iStent & PCS & 80 subjects & 48 mo: -41.36 & $\mathrm{n} / \mathrm{a}$ \\
\hline ECP & Pantalon et al. ${ }^{[21]}$ & $+C E+2$ iStent & PCS & 63 eyes & 12 mo: -34.65 & 12 mo: -0.98 \\
\hline \multicolumn{7}{|c|}{ Subconjunctival space } \\
\hline XEN Gel Stent & $\begin{array}{l}\text { Olgun et al. }{ }^{[15]} \\
\text { Karimi et al. }{ }^{[22]} \\
\text { Wagner et al. } \\
\text { Gillmann et al. }{ }^{[24]}\end{array}$ & $\begin{array}{l}+/-C E \\
+/-C E \\
\text { Standalone } \\
+/-C E\end{array}$ & $\begin{array}{l}\text { RCS } \\
\text { RCS } \\
\text { RCS } \\
\text { PCS }\end{array}$ & $\begin{array}{l}114 \text { eyes } \\
226 \text { subjects } \\
171 \text { eyes } \\
110 \text { eyes }\end{array}$ & $\begin{array}{l}24 \text { mo: }-41.8 \\
18 \text { mo: }-30.05 \\
12 \text { mo: }-37.89 \\
24 \text { mo: }-27.53\end{array}$ & $\begin{array}{l}24 \text { mo: }-2 \\
18 \text { mo: }-1.5 \\
12 \text { mo: }-1.7 \\
24 \text { mo: }-1.45\end{array}$ \\
\hline MicroShunt & Sadruddin et al. ${ }^{[25]}$ & $+/-\mathrm{CE}$ & RA & 23 patients & 36 mo: -44.96 & 36 mo: -1.7 \\
\hline
\end{tabular}

CE: Cataract extraction; PCS: prospective case series; RCS: retrospective case series; RCT: randomised controlled trial; SR/MA: systematic review and meta-analysis; RA: review article.

OR trabecular)]. After this, 2 reviewers (K.K. and P.R.) independently screened the retrieved records to identify eligible studies with discrepancies resolved by discussion. The reference lists of the searched studies were also analysed to identify any suitable papers that were not identified by the search. The initial screening was performed based on title and abstract for relevance, with subsequent in-depth screenings based on full-text analysis. The 2 reviewers (K.K and P.R) then selected the most significant articles for each MIGS technique from the eligible studies for inclusion, based on a ranking criteria, prioritising studies on the strength of their design, recency, and the size of the study.

\section{RESULTS}

\section{Description of included trials}

484 papers were identified from the literature search. The abstracts of these papers were screened by 2 authors. 8 papers were excluded as duplicates, and 313 were excluded for not meeting the inclusion criteria, 163 papers were selected as relevant based on the specified search criteria. Using these relevant articles, 2 authors independently prepared a list of the most significant publications for each MIGS technique based on study size, recency and strength of the study design. After cross-referencing both lists, the 2 authors reached a consensus as to the articles which would be included in the review, and this decision was reviewed by senior authors. After resolving discrepancies in the lists, 25 studies were finally included in the review (details listed comprehensively in Supplementary Table 1).

Key statistics on mechanism of action, effectiveness, and safety profile were extracted for each type of MIGS (an overview of these findings summarised in Table 2). Analysed procedures were limited to 


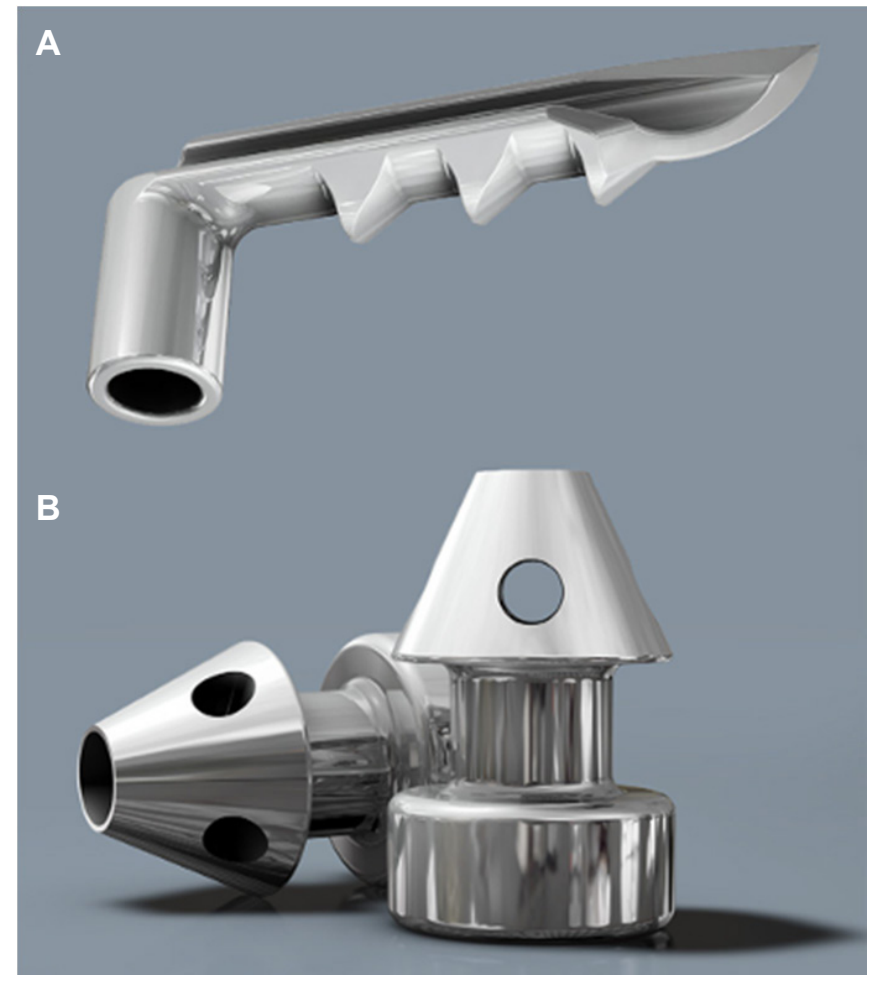

Figure 1. First generation iStent trabecular microbypass stent (A). Second generation iStent inject trabecular microbypass stent (B). This figure is quoted with permission from Hooshmand et al. ${ }^{[5]}$.

MIGS procedures that have a reasonable evidence base. MIGS approaches that were identified include: iStent, iStent inject, Hydrus, Ab-interno Canaloplasty, Trabectome, CyPass, iStent Supra, Xen, Preserflo microshunt, Endocyclophotocoagulation, SLT and the emerging MIGS including MINIject, Beacon Aqueous Microshunt and the extended-release drug delivery systems.

\section{THE DIFFERENT TYPES OF MIGS APPROACHES}

Including mechanism of action, effectiveness, and safety profile.

\section{MIGS aimed at improving outflow through Schlemm's canal}

iStent and iStent inject: Mechanism of action

The iStent and iStent inject (Glaukos Inc, Laguna Hills, CA, USA) are first and second generation trabecular microbypass stents, aimed at improving outflow of aqueous humor through the trabecular meshwork into Schlemm's canal (both pictured in Figure 1$)^{[5]}$. Both are made of heparin coated titanium, and while the iStent is $1 \mathrm{~mm} \times 0.3 \mathrm{~mm}$ in size, the iStent inject is significantly smaller at only $360 \mu \mathrm{m} \times$ $230 \mu \mathrm{m}$ in size. Both are inserted using a disposable implantation device through a clear corneal incision as a single procedure or in combination with cataract extraction, and in the case of iStent inject 2 devices are loaded into the injector and can be placed at $30^{\circ}-60^{\circ}$ apart. Both devices are usually followed up with a 4-week course of topical anti-inflammatory and anti-infective medication to reduce the risk of surgical complications ${ }^{[26]}$. Generally, iStent or iStent inject is indicated in mild to moderate glaucoma with the aim to reduce dependence on topical medications and/or to reduce IOP. These trabecular microbypass devices have an advantage in that they are very small devices, and so are unlikely to cause endothelial damage in patients with shallow anterior chambers. 


\section{iStent and iStent inject: Effectiveness}

Hooshmand et al.$^{[5]}$ found that iStent and iStent inject (both combined with phacoemulsification) had comparable effectiveness in practice, with their study of 145 eyes with primary OAG showing 56.0\% of the iStent and $51.3 \%$ of the iStent inject eyes achieved an IOP value of $\leq 18 \mathrm{mmHg}$ and were medication free at 12 months. In a randomised prospective trial conducted by Samuelson et al ${ }^{[10]}$, iStent inject with phacoemulsification was compared with phacoemulsification alone in terms of safety and efficacy. The proportion of eyes that had achieved an IOP reduction of $\geq 20 \%$ from baseline at 24 -month follow-up was $75.8 \%$ in treatment eyes compared with $61.9 \%$ of eyes in the control group. $84 \%$ of treatment eyes compared with $67 \%$ of control eyes were medication free at the 23 -month follow-up ${ }^{[10]}$.

It has also been demonstrated in an RCT by Katz et al. ${ }^{[9]}$ that increasing the number of iStent devices implanted as a standalone procedure leads to an increased treatment effect. Whilst all patients in this trial were taking between one to three topical medications pre-implantation, all were taken off post-operatively, and in the 1-iStent group 18/38 participants required the addition of a topical medication by 42 months, compared with $4 / 41$ in the 2 -iStent group and $3 / 40$ in the 3 -iStent group ${ }^{[9]}$.

iStent trabecular microbypass devices have also demonstrated efficacy in secondary OAG. In one 24-eye study of iStent in combination with phacoemulsification in pigmentary glaucoma there was a reduction in IOP from $19.50 \pm 6.7 \mathrm{mmHg}$ at baseline to $14.68 \pm 3.0 \mathrm{mmHg}(P<0.01)$ at 36 months in addition to a reduction in medications from $0.75 \pm 1.0$ topical medications to $0.59 \pm 0.6(P>0.05)^{[6]}$. Pseudoexfoliation glaucoma was also investigated by Ferguson et al..$^{[7]}$, with iStent implantation in combination with phacoemulsification in 115 eyes leading to a statistically significant reduction in mean IOP and topical medication usage at 2 years. No studies were identified that solely investigated iStent or iStent inject in steroid induced glaucoma.

\section{iStent and iStent inject: Safety profile}

Samuelson et al..$^{[10]}$ reported the overall adverse events to be less frequent in the intervention group who received iStent and phacoemulsification $(54.1 \%) v s$. the control group (who only received cataract extraction) (62.2\%), and the majority of these were minor complications, the most common being ocular surface disease, stent obstruction, intraocular inflammation, secondary surgical inflammation and ocular allergies. Of those who had stent obstruction $(n=24), 3$ had a laser revision to clear the blockage and these were all successful ${ }^{[10]}$.

\section{Hydrus: Mechanism of action and effectiveness}

The Hydrus microstent (Ivantis inc, Irvine, CA, USA) is an $8-\mathrm{mm}$ intracanalicular scaffold that dilates an entire $90^{\circ}$ quadrant of Schlemm's canal to increase aqueous humor flow through the trabecular meshwork (displayed in Figures 2 and 3). The Hydrus implant is introduced in a fashion similar to other trabecular microbypass stents, through a clear corneal incision with phacoemulsification or as a single procedure, and with the application of a topical corticosteroid and antibiotic solution during the post-operative period. The indication for Hydrus is mild to moderate glaucoma with the aim of reducing dependence on topical medication and to control IOP within a suitable target ${ }^{[26]}$.

The efficacy of Hydrus in combination with phacoemulsification compared to phacoemulsification alone was investigated in the recent HORIZON study by Samuelson et al. In this 369-eye study, an unmedicated IOP reduction of $>20 \%$ was achieved in $77.3 \%$ of Hydrus eyes compared with $57.8 \%$ of control eyes at 24 months. There was a mean reduction of $7.6 \pm 4.1 \mathrm{mmHg}$ in the Hydrus group and $5.3 \pm 3.9 \mathrm{mmHg}$ in the phacoemulsification alone group. Mean medication burden was reduced from $1.7 \pm 0.9$ pre-operatively (baseline value in both intervention and control was equivalent) to $0.3 \pm 0.8$ in the Hydrus group and to 0.7 \pm 0.9 in the phacoemulsification alone group ${ }^{[4]}$. 


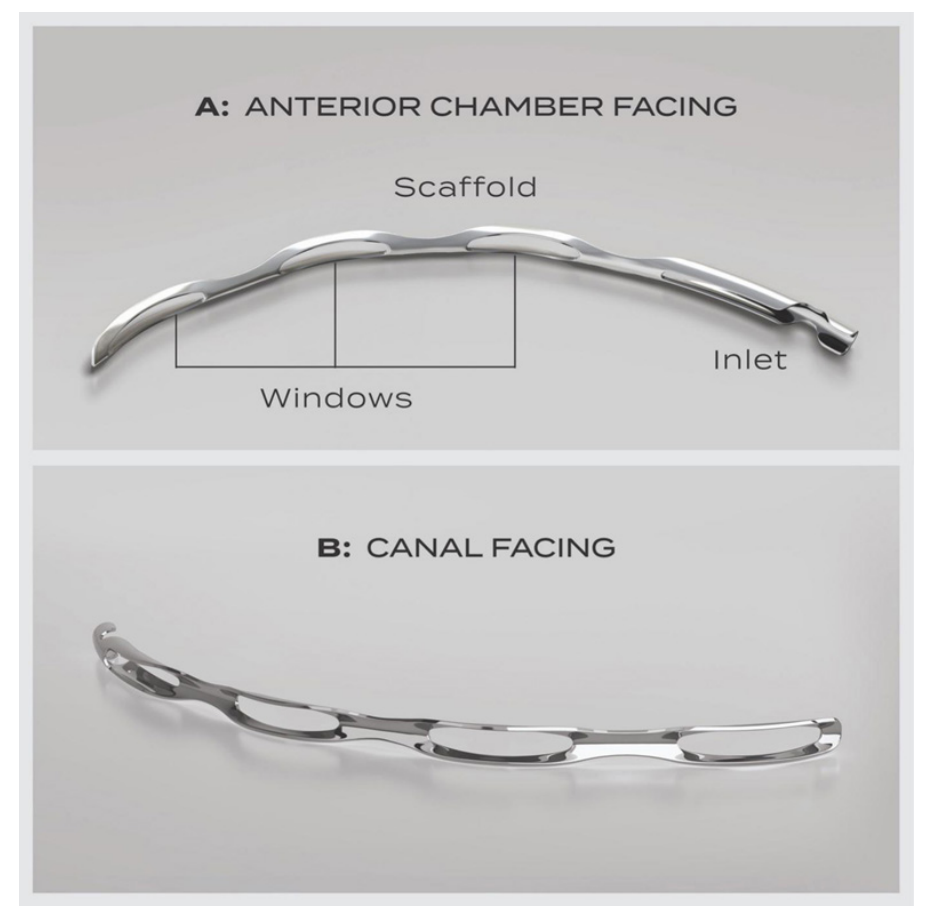

Figure 2. Hydrus microstent (Ivantis inc, Irvine, CA, USA). (A) diagram of the Hydrus microbypass stent with the anterior chamber forward. (B) is an image of the posterior chamber. Image copyright of Ivantis, Inc.

Hydrus was also investigated as a head-to-head comparison with 2 first-generation iStent (both performed following uncomplicated cataract surgery) in the COMPARE trial, a 152-patient randomised clinical trial by Ahmed et al. ${ }^{[8]}$ It was concluded in this study that Hydrus reduced IOP at 12 months by $1.7 \pm 4.0 \mathrm{mmHg}$ compared with a reduction of $1.0 \pm 4.0 \mathrm{mmHg}$ in the 2 -iStent group, a difference of $0.7 \mathrm{mmHg}$ (95\% CI: -2.0-0.7). Medication reduction was also greater as Hydrus achieved a reduction of $1.6 \pm 1.2$ medications $v s$. $1.0 \pm 1.2$ in the 2-iStent group, a difference in 0.6 medications (95\%CI: 0.9-0.2). Interestingly, Hydrus was able to achieve a $\geq 20 \%$ IOP improvement in $39.7 \%$ of patients compared with only $13.3 \%$ in the 2 -iStent group and was able to achieve $30.1 \%$ in the $\leq 18 \mathrm{mmHg}$ category compared with only $9.3 \%$ in the 2 -iStent $\operatorname{group}^{[8]}$.

\section{Hydrus: Safety profile}

Adverse events were roughly comparable between both of the groups in the COMPARE trial in terms of BCVA loss, IOP spikes, new cataracts and device obstruction. 2 patients in the Hydrus $(n=74)$ and 1 in the 2 -iStent $(n=76)$ experienced a BCVA loss of $>2$ lines at 12 months, and IOP spikes of $>10 \mathrm{mmHg}$ were seen in 3 patients in the Hydrus group and 4 patients in the 2 -iStent group. New cataracts were seen in 2 patients in the Hydrus group and in 1 patient in the 2 -iStent group and device obstruction due to any cause was seen in 9 of the Hydrus and 10 of the 2 -iStent patients.

Safety of the Hydrus microstent was generally reflective of the safety of other trabecular microbypass devices. There was also no need for any incisional glaucoma surgery in the Hydrus group compared with in the 2 -iStent group, where 2 patients (of 76 in that group) required a secondary trabeculectomy and 1 patient required a cataract surgery ${ }^{[8]}$.

\section{Ab-interno canaloplasty: Mechanism of action and efficacy}

$\mathrm{Ab}$-interno canaloplasty $(\mathrm{ABiC})$ is a procedure where a microcatheter such as the iTrack device (Ellex Medical Lasers Pty Ltd, Adelaide, Australia) is used to perform $360^{\circ}$ viscodilation of Schlemm's canal, 


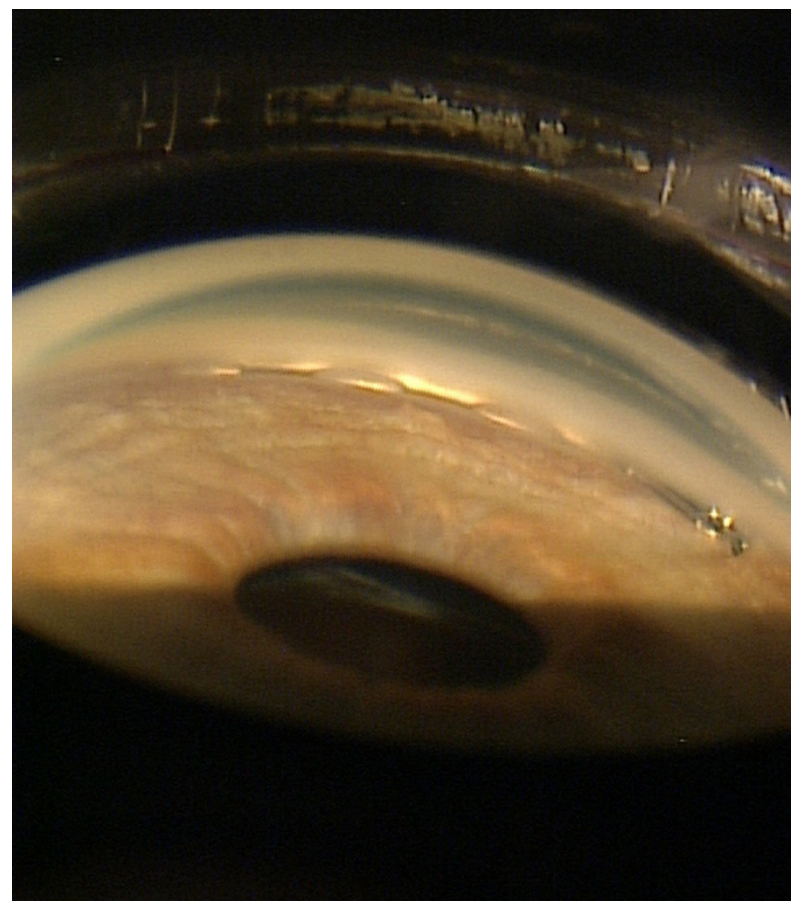

Figure 3. Hydrus microstent (Ivantis inc, Irvine, CA, USA) viewed gonioscopically in position in the canal of Schlemm. The device is partially obscured by the overlying trabecular meshwork. Image copyright of Ivantis, Inc.

without the requirement for suturing. This acts to reduce IOP by dilating the canal of Schlemm and downstream collector channels to improve aqueous outflow. The indication for $\mathrm{ABiC}$ in mild to moderate glaucoma is either as a solo procedure or in combination with other forms of trabecular microbypass devices to facilitate further dilation of the collecting channels, and greater outflow than would be achieved with these devices alone, a similar principle to other non-implantation techniques specifically targeting improved outflow through Schlemm's canal.

$\mathrm{ABiC}$ has been evaluated as both a sole procedure in phakic eyes and in combination with cataract surgery by Davids et al. ${ }^{[1]}$ In one study of 36 eyes (20 pseudophakic and 16 phakic) a reduction in mean IOP was seen from $19.8 \pm 4.1 \mathrm{mmHg}$ pre-operatively to $13.8 \pm 3 \mathrm{mmHg} 12$ months post-operatively across the 2 groups $^{[11]}$. There was, however, no statistically significant reduction in the number of medications during this period, which stabilised at $2.1 \pm 1.6(P=1.0)$. This would be an important point to include when counselling patients about $\mathrm{ABiC}$ as a sole procedure ${ }^{[11]}$.

$\mathrm{ABiC}$ also has the potential to be used as a combination therapy with other forms of MIGS. Heersink et al ${ }^{[12]}$ explored this concept in their 186-eye retrospective study comparing iStent and cataract surgery with iStent, $\mathrm{ABiC}$ and cataract surgery. The results showed a clear favourability for the IOP lowering effects of iStent with $\mathrm{AbiC}$ and phacoemulsification, as this group achieved a mean IOP reduction of $2.9 \pm$ $3.6 \mathrm{mmHg}$ compared with $1.7 \pm 3.1 \mathrm{mmHg}$ in the iStent and phacoemulsification groups alone. The percentage of patients achieving treatment success (a final IOP of $\leq 18 \mathrm{mmHg}$ and a mean reduction in IOP of $>20 \%$ ) was $46 \%$ in the combined group compared with $35 \%$ in the trabecular microbypass and cataract surgery alone group. In terms of medication, $56 \%$ of patients in the combined group were off all medications compared with $48 \%$ in the control group, a mean reduction of 0.9 and 0.7 , respectively ${ }^{[12]}$.

It is likely that $\mathrm{ABiC}$ would be an effective procedure to combine with existing trabecular microbypass methods. As a sole procedure it is also effective at lowering IOP; however, it has showed limited efficacy in 
medication reduction so far and this will need to be taken into account when considering its use in patients with a high medication burden.

\section{Ab-interno canaloplasty: Safety profile}

Safety appears to be favourable, and according to Heersink et al. ${ }^{[12]}$, inflammation was the most common adverse event in the combined group and occurred in $6 \%$ of participants, while loss of visual acuity was the most common adverse event in the control group, occurring in $8 \%$ of participants.

\section{Trabectome: Mechanism of action and efficacy}

Trabectome or ab-interno trabeculectomy achieves an increase in aqueous humor outflow through the trabecular meshwork by applying a $0.8 \mathrm{~W}$ electrical current in order to ablate the trabecular meshwork. Access to the anterior chamber is achieved through a clear corneal incision and gonioscopy is used intraoperatively to visualise the trabecular meshwork. Trabectome and $\mathrm{ABiC}$ are significantly differentiated from the other trabecular microbypass techniques, as no indwelling devices are left in the eye after the operation. Esfandiari et al. ${ }^{[13]}$ demonstrated the efficacy of Trabectome when compared against iStent implantation (both with phacoemulsification), and after 24 months a mean IOP of $13.9 \pm 3.3 \mathrm{mmHg}$ was achieved in Trabectome patients $(n=154)$ compared with $16.8 \pm 2.8 \mathrm{mmHg}$ in iStent $(n=110)$ from a baseline of $15.3 \pm 3.1 \mathrm{mmHg}$ in both groups. Medication burden was $0.7 \pm 1.0$ and $1.7 \pm 1.2 \mathrm{in}$ the trabectome and iStent groups, respectively, at 24 months. In addition, the proportion of eyes with an unmedicated IOP of $\leq 21 \mathrm{mmHg}$ was $53 \%$ and $16.6 \%$ in the trabectome and iStent eyes, respectively ${ }^{[13]}$.

Trabectome has also demonstrated efficacy in pseudoexfoliative glaucoma. Avar et al. ${ }^{[14]}$ investigated Trabectome performed on patients either as a solo procedure or with concomitant cataract extraction (in combined data) described a significant IOP lowering effect in $28 \%$ of patients with POAG and $26 \%$ with pseudoexfoliative glaucoma, as well as a significant medication reduction in $32 \%$ and $29 \%$, respectively. The median follow-up period in this study was 3.5 years $^{[14]}$.

\section{Gonioscopy assisted transluminal trabeculotomy}

Gonioscopy assisted transluminal trabeculotomy (GATT) is a procedure where a circumferential trabeculotomy is performed of the trabecular meshwork, by running a suture the entire length of Schlemm's canal, retrieving and pulling the distal tip while applying traction to the proximal end of the suture. A study of XEN compared with GATT (both with or without cataract extraction, in combined data) showed that IOP was reduced from $24.9 \pm 5.8 \mathrm{mmHg}$ to $15.3 \pm 3.8 \mathrm{mmHg}$ at 24 months post-operatively, and medications were reduced from $3.3 \pm 0.6$ to $1.2 \pm 0.4$. This is compared to a reduction in IOP from $24.4 \pm$ $4.3 \mathrm{mmHg}$ to $14.2 \pm 2.2 \mathrm{mmHg}$ at 24 months and medication reduction from $3.4 \pm 0.5$ to $2.0 \pm 2.2$ over the same period for the XEN gel stent. Transient hyphaema was the most common post-operative complication following GATT, occurring in $28 \%$ of patients ${ }^{[15]}$.

\section{Excisional goniotomy}

Excisional goniotomy or trabeculotomy facilitates increased aqueous outflow by utilising a device such as the Kahook Dual Blade (KDB, New World Medical, Rancho Cucamonga, CA) to incise the trabecular meshwork and in theory avoid the thermal damage associated with Trabectome or leaving remnant trabecular meshwork leaflets in-situ such as with GATT. In a 315-eye study comparing both iStent and Kahook Dual Blade in combination with phacoemulsification found that the mean IOP reduction at 12 months was $5.0 \mathrm{mmHg}$ compared with $2.3 \mathrm{mmHg}$ in the iStent group $(P<0.001)$ and mean medication reductions were similar in both groups with 1.03 and 0.97 in the Kahook Dual Blade group and the iStent group, respectively. Transient IOP elevation and transient anterior chamber inflammation were the most complications following KDB, both occurring in $1 \%$ of patients ${ }^{[16]}$. 


\section{MIGS aimed at creating an outflow channel to the supraciliary space}

Mechanism of action, effectiveness, and safety profile.

CyPass: Mechanism of action and efficacy

CyPass (Transcend Medical Inc, Menlo Park, CA, USA) was a tubular stent which aimed to reduce IOP by shunting fluid through a passage into the supraciliary space. It was performed through a clear corneal incision, and the stent is placed inferior to the trabecular meshwork and advanced into the suprachoroidal space. CyPass had proven efficacy in the COMPASS trial which compared CyPass combined with phacoemulsification to phacoemulsification alone. It was shown that at 2 years, patients who had received the CyPass microstent had a mean reduction in IOP of $7.4 \pm 4.4 \mathrm{mmHg}(30 \%)$ compared to $5.4 \pm 3.9 \mathrm{mmHg}$ (21\%) in the control group $(P<0.001$ for CyPass microstent $v$ s. control). A reduction from baseline values of $17.0 \pm 3.4 \mathrm{mmHg}$ and $19.3 \pm 3.3 \mathrm{mmHg}$, respectively. This efficacy was also shown in the reduction in medications, as medications at 2 years had dropped from $1.4 \pm 0.9$ to $0.2 \pm 0.6$ in the CyPass group and from $1.3 \pm 1.0$ to $0.6 \pm 0.8$ in the control group. At 2 years $85 \%$ of CyPass recipients had maintained their IOP with no medications, compared to $59 \%$ in the phacoemulsification alone cohort ${ }^{[17]}$.

CyPass has also been compared with iStent in a head-to-head meta-analysis by Fard et al ${ }^{[19]}$, and in that study, they showed that CyPass alone (without phacoemulsification) was a more effective intervention for reducing IOP than either 1 or $\geq 2$ iStents with or without phacoemulsification, but both techniques were comparable in terms of medication reduction.

\section{CyPass: Safety concerns}

The COMPASS XT study was an extension of the original 24-month study for an additional 36 months to assess the safety of the stent. This study showed comparable safety between the study and control groups, and while there were 2 sight threatening complications in the CyPass group compared with only one in the control group, these were deemed to be unrelated to the stent. Despite this, evidence was found for increased corneal endothelial cell loss compared with the group that underwent phacoemulsification alone, and due to this it was announced in August 2018 that it would be voluntarily removed from the market by Alcon due to the potential risks, with the potential for reintroduction in the future ${ }^{[18]}$.

iStent Supra: Mechanism of action, effectiveness, and safety profile

iStent Supra (Glaukos Inc, Laguna Hills, CA, USA) is currently an experimental microbypass stent which also harnesses the uveoscleral pathway similarly to CyPass. Myers et al. ${ }^{[20]}$ evaluated iStent Supra in combination with 2 iStents and post-operative Travoprost for the treatment of refractory open angle glaucoma following trabeculectomy and maximal medical therapy. The pre-operative mean medicated IOP was $22.0 \pm 3.1 \mathrm{mmHg}$, with $1.2 \pm 0.4$ medications on average. The post-operative mean medicated IOP at 48 months was $\leq 13.7 \mathrm{mmHg}(12.9 \pm 0.9 \mathrm{mmHg}$ at month 48$)$ and unmedicated mean IOP was $18.4 \pm$ $1.4 \mathrm{mmHg}$ at month 49 (post-washout). The safety profile of the suprachoroidal stent was favourable, and throughout the 48-month follow-up no patients required additional glaucoma surgery ${ }^{[20]}$.

Assessing the efficacy of iStent supra in this form of study alone is challenging, as there are confounding variables in the form of the 2 iStent devices, and the effects of the topical Travoprost. Further studies to determine the efficacy of iStent supra would be beneficial, preferably in the form of randomised controlled studies, and in comparison, with other methods or in combination with phacoemulsification.

\section{MIGS targeted at the subconjunctival space}

Mechanism of action, effectiveness, and safety profile. 


\section{Xen: Mechanism of action and effectiveness}

The XEN gel implant (Allergan inc, Irvine, CA, USA) was a form of MIGS targeting aqueous outflow to the subconjunctival space; however, in November 2019, Allergan Australia Pty Ltd. announced that there would be a voluntary global recall of all un-implanted XEN units due to a portion of them failing quality control. They did not recommend the explantation of implants that had already been placed ${ }^{[27]}$.

The XEN gel stent was implanted into the trabecular meshwork with a needle through an ab-interno approach, which was then advanced to puncture the sclera entirely and pass the flexible stent into the subconjunctival space. This then creates a channel for aqueous humour outflow and creates an internal bleb to reduce IOP. XEN was indicated for moderate to advanced glaucoma, as it was a bleb-based procedure with the associated risks/complications associated with this. Karimi et al. ${ }^{[22]}$ investigated the efficacy of XEN alone or in combination with phacoemulsification with a 259 eye consecutive case series. The results showed that mean IOP (of both groups combined) was reduced from $19.3 \pm 6.0 \mathrm{mmHg}$ at baseline to $13.5 \pm$ $3.3 \mathrm{mmHg}$ at 18 -month follow-up, and medications were reduced from $2.6 \pm 1.1$ to $1.1 \pm 1.3$ at 18 months. It was also interesting to note that simultaneous cataract extraction or solo stent implantation did not significantly impact outcomes, as these groups had an IOL of $13.8 \pm 2.6 \mathrm{mmHg}$ and $14.3 \pm 4.7 \mathrm{mmHg}$ at 12-month follow-up, respectively $(P=0.5367)^{[22]}$.

As a form of bleb forming procedure, it is also important to compare the XEN gel stent with trabeculectomy, which is still the predominant incisional procedure for glaucoma. Wagner et al. ${ }^{[23]}$ compared the 2 as standalone procedures performed in a 171-eye study, which demonstrated that complete surgical success at 12 months post-operative follow-up was higher in the trabeculectomy group at $65.5 \%$ (95\%CI: 55.6\%-75.9\%) compared with the XEN gel stent group at 58.5\% (95\%CI: 47.6\%-69.4\%). There was however no significant difference between both groups' surgical outcomes $(P=0.16)$. In addition, an IOP reduction at 12 -month follow-up of $7.2 \pm 8.2 \mathrm{mmHg}$ in the XEN group and $10.5 \pm 9.2 \mathrm{mmHg}$ in the trabeculectomy group were observed from baseline values of $19.0 \mathrm{mmHg}(95 \% \mathrm{CI}: 16.8-25.0 \mathrm{mmHg}$ ) and $21.0 \mathrm{mmHg}$ (95\%CI: 17.0-27.0 mmHg), respectively $(P=0.003)$. Medication reduction was also reduced to $0.3 \pm 0.5$ and $0.2 \pm 0.4$ in the XEN and trabeculectomy cohorts, respectively from baseline values of 2.0 (95\%CI: 1.0-3.0) and 3.0 (95 CI: 2.0-4.0), respectively ${ }^{[23]}$.

The XEN gel stent was also shown to have comparable efficacy in other secondary forms of open angle glaucoma, including pseudo exfoliation glaucoma as demonstrated by Gillmann et al ${ }^{[24]}$, where 110 eyes with either pseudoexfoliative OAG or POAG underwent either XEN as a standalone or with cataract surgery (with data combined). In this study the mean medicated IOP was $14.2 \pm 3.8 \mathrm{mmHg}$ (a $28.3 \%$ reduction) in the pseudoexfoliative group compared with $14.5 \pm 3.6 \mathrm{mmHg}$ (a $26.8 \%$ reduction) in the POAG group after 2 years, a reduction from $19.8 \pm 8.2 \mathrm{mmHg}$ and $19.8 \pm 5.8 \mathrm{mmHg}$ respectively. Medication reduction was also comparable, with a drop from $2.0 \pm 1.3$ to $0.4 \pm 0.7$ in pseudoexfoliation glaucoma and from $1.9 \pm 1.6$ to $0.6 \pm$ 0.9 in POAG. Success rates were not different to a statistically significant degree, and the rate of adverse effects and rates of needling were similar in both groups (42.8\% POAG vs. $43.2 \%$ pseudoexfoliative) ${ }^{[24]}$. There were no studies showing evidence of the efficacy of the XEN implant in pigmentary or steroid induced glaucoma.

\section{Xen: Safety profile}

Important to note is that $40.9 \%$ of cases required post-operative management including bleb needling or the administration of an antimetabolite injection, and adverse events included IOP spikes of $\geq 30$ $\mathrm{mmHg}(12.7 \%)$, follow-up glaucoma filtration surgery (9.3\%), exposure of the implant (2.3\%) aswell as some cases of persistent hypotonous maculopathy, persistent choroidal effusions, a cyclodialysis cleft and endophalmitis following bleb resuturing ${ }^{[22]}$. This is partially to be expected with a bleb forming operation and reflects the safety profile of this class of procedure. 
The Preserflo microshunt (Santen Inc, Emeryville, CA, USA) previously known as the InnFocus microshunt aims to address the need for a form of MIGS that can be effectively applied to moderate to severe glaucoma. The Preserflo device is implanted into the subconjunctival space below Tenon's capsule via an ab-externo approach and threaded through a needle tunnel into the anterior chamber. The biocompatible material of the Preserflo tube (SIBS) in combination with intraoperative Mitomycin C is used to reduce the risk of scarring and fibrosis. Sadruddin et al ${ }^{[25]}$ showed in a 23 patient post-market study of Preserflo with and without phacoemulsification, a reduction from the mean baseline IOP in both groups of $23.8 \pm$ $5.3 \mathrm{mmHg}$ (26.4 $\mathrm{mmHg}$ in phacoemulsification combination group vs. $22.1 \mathrm{mmHg}$ for Preserflo alone) to $10.7 \pm 3.5 \mathrm{mmHg}$ at 3-years follow-up $(10.2 \mathrm{mmHg}$ with phacoemulsification $v$ s. $11.1 \mathrm{mmHg}$ for Preserflo alone). Medication reduction was $71 \%$ overall at 3 years, and $64 \%$ of participants no longer required topical glaucoma medications ${ }^{[25]}$.

Transient hypotony, shallow anterior chambers and the device touching the iris occurred in $13 \%$ of patients individually, while transient choroidal detachment, hyphema and exposed Tenon's capsule were also common adverse events occurring in $9 \%$ of patients respectively. All of these issues resolved spontaneously within 3 months of surgery being performed ${ }^{[25]}$.

There is currently a lack of randomised control trials on the efficacy of Preserflo, however one RCT is in progress and with more high-level evidence the safety and efficacy of this novel method will be made increasingly clear in order to establish it as a viable option in OAG management.

\section{MIGS targeting the ciliary process}

Endocyclophotocoagulation: Mechanism of action, effectiveness and safety profile Endocyclophotocoagulation (ECP) is a procedure that can be performed in conjunction with phacoemulsification for refractory glaucoma and aims to reduce the production of aqueous humor by the ciliary processes by shrinking these using a directed laser. ECP is generally indicated in end-stage glaucoma. Pantalon et al. ${ }^{[21]}$ have demonstrated the efficacy of ECP through conducting a 12-month retrospective study with patients receiving either 2 iStents, with concurrent ECP and cataract extraction, or phacoemulsification and 2 iStents alone. The ECP procedure proved efficacious in reducing IOP from a baseline value of $19.97 \pm 4.31 \mathrm{mmHg}$ to $13.05 \pm 2.18 \mathrm{mmHg}$ (a 35\% reduction) compared with $17.63 \pm$ $3.86 \mathrm{mmHg}$ to $14.09 \pm 1.86 \mathrm{mmHg}$ (a $21 \%$ reduction) in the phacoemulsification and 2 iStent alone group. Medications were also reduced from $2.22 \pm 1.6$ to $1.24 \pm 1.05$ in the ECP group and from $2.07 \pm 1.02$ to $1.39 \pm 1.03$ in the phaco-iStent alone group, a comparable reduction in both, and safety results were also comparable. These results appear promising for the utilisation of ECP as a combined procedure with other MIGS and cataract surgery ${ }^{[21]}$.

There is, however, limited knowledge of the safety profile of ECP due to the lack of high-level evidence in the form of randomised controlled trials. One study, currently in the data collection phase, is investigating patients with POAG receiving either ECP with phacoemulsification or phacoemulsification as a standalone procedure $^{[28]}$.

\section{Emerging MIGS procedures}

\section{MINIject}

The MINIject device (iStar Medical, Wavre, Belgium) is a $4 \mathrm{~mm}$ stent designed to follow the curvature of the sclera and utilises porous silicone to allow aqueous outflow via the uveoscleral pathway. No studies were identified investigating the MINIject device, and this is an area where more evidence is required before a clear comment can be made about this form of MIGS ${ }^{[2]]}$. 
This device is designed to reduce IOP by shunting aqueous fluid onto the ocular surface via a clear corneal incision. There are currently no clinical trials on this device ${ }^{[29]}$.

\section{CONCLUSION}

Minimally invasive glaucoma surgery has, for several years, been a disrupting force in the area of glaucoma management and is a therapy that has effectively established itself between medical management and more invasive glaucoma surgery. MIGS offer significant advantages in terms of safety and efficacy for the patient with mild to moderate glaucoma and a significant medication burden. As this area of glaucoma surgery continues to grow, so too will the evidence in support of MIGS as a legitimate intermediate step in the glaucoma management pathway.

\section{DECLARATIONS}

\section{Authors' contributions}

Made substantial contributions to conception and design of the study and performed data analysis and interpretation: Komzak K, Rothschild P, Hooshmand J, Allen P, Toh T

\section{Availability of data and materials}

Not applicable.

\section{Financial support and sponsorship}

None

\section{Conflicts of interest}

All authors declared that there are no conflicts of interest

\section{Ethical approval and consent to participate}

Not applicable.

\section{Consent for publication}

Not applicable.

\section{Copyright}

(c) The Author(s) 2021.

\section{REFERENCES}

1. Weinreb RN, Aung T, Medeiros FA. The Pathophysiology and Treatment of Glaucoma. JAMA 2014;311:1901-11.

2. McClelland JF, Bodle L, Little JA. Investigation of medication adherence and reasons for poor adherence in patients on long-term glaucoma treatment regimes. Patient Prefer Adherence 2019;13:431-9.

3. Eldaly MA, Bunce C, Elsheikha OZ, Wormald R. Non-penetrating filtration surgery versus trabeculectomy for open-angle glaucoma. Cochrane Database Syst Rev 2014:CD007059.

4. Samuelson TW, Chang DF, Marquis R, et al. A Schlemm canal microstent for intraocular pressure reduction in primary open-angle glaucoma and cataract: The HORIZON study. Ophthalmology 2019;126:29-37.

5. Hooshmand J, Rothschild P, Allen P, Kerr NM, Vote BJ, Toh T. Minimally invasive glaucoma surgery: Comparison of iStent with iStent inject in primary open angle glaucoma. Clin Exp Ophthalmol 2019;47:898-903.

6. Ferguson TJ, Ibach M, Schweitzer J, Karpuk KL, Stephens JD, Berdahl JP. Trabecular micro-bypass stent implantation with cataract extraction in pigmentary glaucoma. Clin Exp Ophthalmol 2020;48:37-43.

7. Ferguson TJ, Swan R, Ibach M, Schweitzer J, Sudhagoni R, Berdahl JP. Trabecular microbypass stent implantation with cataract extraction in pseudoexfoliation glaucoma. J Cataract Refract Surg 2017;43:622-6.

8. Ahmed IIK, Fea A, Au L, et al. A prospective randomized trial comparing hydrus and iStent microinvasive glaucoma surgery implants for standalone treatment of open-angle glaucoma: The COMPARE study. Ophthalmology 2020;127:52-61.

9. Katz LJ, Erb C, Carceller Guillamet A, et al. Long-term titrated IOP control with one, two, or three trabecular micro-bypass stents in 
open-angle glaucoma subjects on topical hypotensive medication: 42-month outcomes. Clin Ophthalmol 2018;12:255-62.

10. Samuelson TW, Sarkisian SR Jr., Lubeck DM, et al. Prospective, randomized, controlled pivotal trial of an Ab interno implanted trabecular micro-bypass in primary open-angle glaucoma and cataract: two-year results. Ophthalmology 2019;12:811-21.

11. Davids AM, Pahlitzsch M, Boeker A, Winterhalter S, Maier-Wenzel AK, Klamann M. Ab interno canaloplasty (ABiC)-12-month results of a new minimally invasive glaucoma surgery (MIGS). Graefes Arch Clin Exp Ophthalmol 2019;257:1947-53.

12. Heersink M, Dovich JA. Ab interno canaloplasty combined with trabecular bypass stenting in eyes with primary open-angle glaucoma. Clin Ophthalmol 2019;13:1533-42.

13. Esfandiari H, Taubenslag K, Shah P, et al. Two-year data comparison of ab interno trabeculectomy and trabecular bypass stenting using exact matching. J Cataract Refract Surg 2019;45:608-14.

14. Avar M, Jordan JF, Neuburger M, et al. Long-term follow-up of intraocular pressure and pressure-lowering medication in patients after ab-interno trabeculectomy with the Trabectome. Graefes Arch Clin Exp Ophthalmol. 2019;257:997-1003.

15. Olgun A, Aktas Z, Ucgul AY. XEN gel implant versus gonioscopy-assisted transluminal trabeculotomy for the treatment of open-angle glaucoma. Int Ophthalmol 2020;40:1085-93.

16. ElMallah MK, Seibold LK, Kahook MY, et al. 12-month retrospective comparison of Kahook dual blade excisional goniotomy with istent trabecular bypass device implantation in glaucomatous eyes at the time of cataract surgery. Adv Ther 2019;36:2515-27.

17. Vold S, Ahmed, II, Craven ER, et al. Two-year COMPASS trial results: supraciliary microstenting with phacoemulsification in patients with open-angle glaucoma and cataracts. Ophthalmology 2016;123:2103-12.

18. Reiss G, Clifford B, Vold S, et al. Safety and effectiveness of cypass supraciliary micro-stent in primary open-angle glaucoma: 5-year results from the COMPASS XT study. Am J Ophthalmol 2019;208:219-25.

19. Mahdavi Fard A, Patel SP, Pourafkari L, Nader ND. Comparing iStent versus CyPass with or without phacoemulsification in patients with glaucoma: a meta-analysis. Ther Adv Chronic Dis 2019;10:2040622318820850.

20. Myers JS, Masood I, Hornbeak DM, et al. Prospective evaluation of two iStent((R)) trabecular stents, one iStent Supra((R)) suprachoroidal stent, and postoperative prostaglandin in refractory glaucoma: 4-year outcomes. Adv Ther 2018;35:395-407.

21. Pantalon AD, Barata ADO, Georgopoulos M, Ratnarajan G. Outcomes of phacoemulsification combined with two iStent inject trabecular microbypass stents with or without endocyclophotocoagulation. Br J Ophthalmol. 2020;104:1378-83.

22. Karimi A, Lindfield D, Turnbull A, et al. A multi-centre interventional case series of 259 ab-interno Xen gel implants for glaucoma, with and without combined cataract surgery. Eye (Lond). 2019;33:469-77.

23. Wagner FM, Schuster AK, Emmerich J, Chronopoulos P, Hoffmann EM. Efficacy and safety of XEN(R)-Implantation vs. trabeculectomy: Data of a "real-world" setting. PLoS One 2020;15:e231614.

24. Gillmann K, Bravetti GE, Mermoud A, Rao HL, Mansouri K. XEN gel stent in pseudoexfoliative glaucoma: 2-year results of a prospective evaluation. J Glaucoma 2019;28:676-84.

25. Sadruddin O, Pinchuk L, Angeles R, Palmberg P. Ab externo implantation of the MicroShunt, a poly (styrene-block-isobutylene-blockstyrene) surgical device for the treatment of primary open-angle glaucoma: a review. Eye Vis (Lond). 2019;6:36.

26. Pillunat LE, Erb C, Junemann AG, Kimmich F. Micro-invasive glaucoma surgery (MIGS): a review of surgical procedures using stents. Clin Ophthalmol. 2017;11:1583-600.

27. Kerr N. MIGS: what's happening now and on the Horizon. Glaucoma Australia 2019. Available from: https://glaucoma.org.au/newsdetails/treatment/migs-whats-happening-now-and-on-the-horizon. [Last Accessed on 1 Mar 2021].

28. Toth M, Shah A, Hu K, Bunce C, Gazzard G. Endoscopic cyclophotocoagulation (ECP) for open angle glaucoma and primary angle closure. Cochrane Database Syst Rev 2019;2:CD012741.

29. Shah M. Micro-invasive glaucoma surgery - an interventional glaucoma revolution. Eye Vis (Lond). 2019;6:29. 